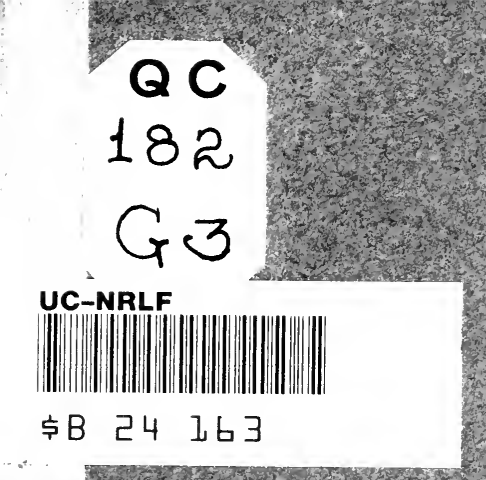




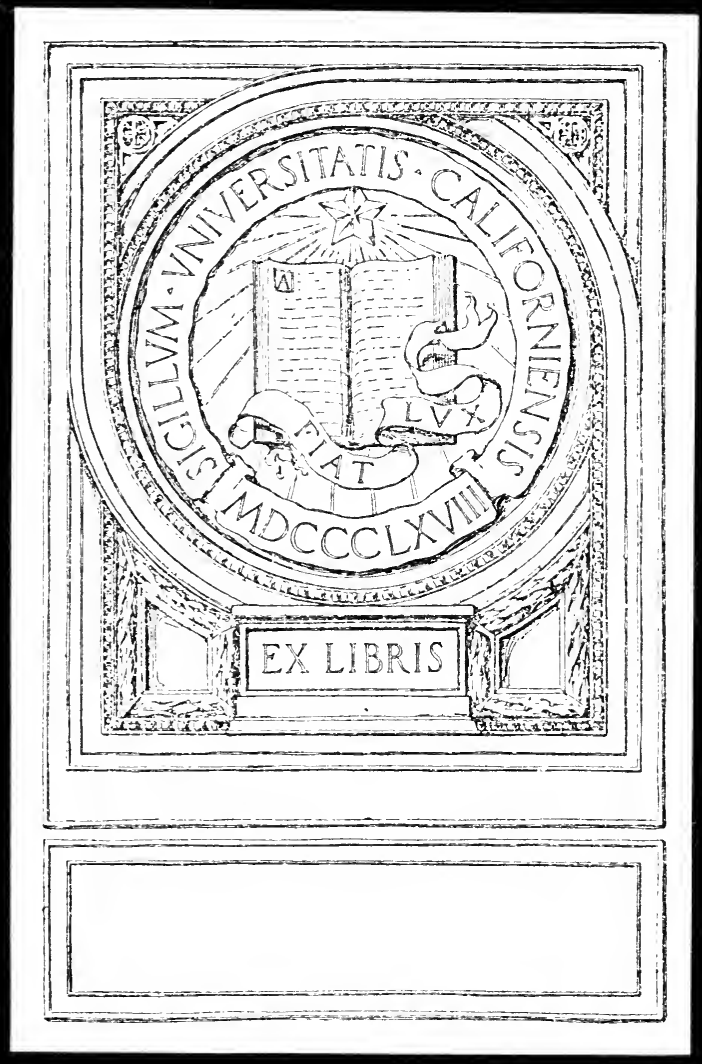


The Influence of Temperature, Pressure and Supporting Material for the Catalyst on the Adsorption of Gases by Nickel

ALFRED WILLIAM GAUGER

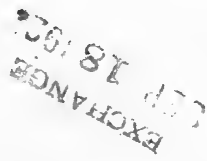





\title{
The Influence of Temperature, Pressure and Supporting Material for the Cata- lyst on the Adsorption of Gases by Nickel
}

A DISSERTATION

PRESENTED TO THE

\author{
Faculty of Princeton University \\ IN Candidacy for THE DEgReE \\ OF DOCTOR OF PHILOSOPHY
}

BY

ALFRED WILLIAM GAUGER 
サ

a

4,15 


\section{THE INFLUENCE OF TEMPERATURE, PRESSURE AND SUPPORTING MATERIAL FOR THE CATALYST ON THE ADSORPTION OF GASES BY NICKEL}

The importance of the determination of the adsorptive power of catalytic materials for various reaction processes has previously been emphasized and the results accruing from a preliminary experimental investigation of a number of metallic hydrogenation catalysts have already been published by 'Taylor and Burns. ${ }^{1}$ The results suggested that the adsorption obtained with a given catalyst might be largely dependent on the method of prepara-

${ }^{1}$ (a) Taylor, J. Ind. Eng. Chem., 13, 75 (1921). (b) Taylor and Burns, J. Am. Chem. Soc., 43, 1277 (1921). 
tion and treatment accorded to the metal prior to the experiments. Furthermore, the variability of adsorption with pressure in the adsorption of hydrogen by nickel as measured in the earlier work seemed to indicate differences from results obtained with adsorbents of the type of charcoal. The different susceptibilities of catalytic agents to heat treatment when spread on support material and, alternatively, when unsupported, suggested also that the adsorptive capacities of catalysts on suitable supports should be studied. The present work presents such a study dealing intensively with nickel as a catalyst and with hydrogen as the adsorbed gas mainly employed.

Apparatus and Manipulation.-The apparatus was essentially the same as that used by Taylor and Burns. A manometer was connected to the adsorption bulb for the pressure measurements. The gas buret employed to measure the gas recovered from the absorption bulb by evacuation through the Töpler pump was graduated to $0.01 \mathrm{cc}$. The sample of nickel nitrate from which the catalyst was prepared was dehydrated at low temperature in a casserole and then placed in the adsorption bulb in an electrically heated furnace as previously described by Taylor and Burns, where it was completely denitrated by a current of air at the temperature of reduction and then reduced by a slow stream of pure dry hydrogen. After reduction it was allowed to cool in the stream of hydrogen, and when the material was cold the hydrogen was replaced by carbon dioxide, the wide end of the bulb quickly closed and the bulb sealed into position in the apparatus, evacuated and filled with hydrogen at $300-310^{\circ}$ to reduce any oxide formed during the transfer. After this final reduction, the bulb was evacuated at $300-310^{\circ}$ until the amount of gas coming off in 10-minute intervals did not exceed $6 \mathrm{cu}$. $\mathrm{mm}$. The heating of the bulb for this reduction and evacuation was accomplished by means of an electrical resistance furnace.

When evacuation was complete, the bulb was cooled to $25^{\circ}$ and maintained at that temperature by a water-bath raised about it. A measured quantity of pure, dry hydrogen was then introduced into the bulb and the pressure on the manometer recorded as soon as equilibrium was reached. Successive small amounts of the gas were then pumped off and measured in the receiving buret which was calibrated to $0.002 \mathrm{cc}$. After each successive volume was removed from the bulb, the pressure of the gas remaining was recorded as soon as equilibrium was attained. When zero pressure at $25^{\circ}$ was reached, the temperature was raised to $300-310^{\circ}$ and the rest of the gas pumped off and measured. From the successive volumes pumped off and the total volume, the volume corresponding to each pressure recorded was calculated. The process was repeated at $80.5^{\circ}, 184^{\circ}, 218^{\circ}$ and $305^{\circ}$. The free space in the bulb was determined at each temperature by admitting pure dry nitrogen at various pressures 


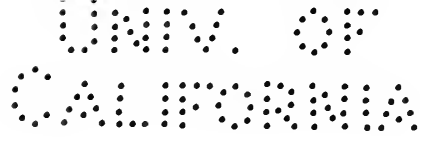

up to atmospheric and recording the volumes. This involves the assumption that nitrogen is not measurably adsorbed by nickel. Experiments with helium as reference gas have justified this assumption. From the difference between the hydrogen value at each pressure measured and the calculated nitrogen value at that pressure the number of cubic centimeters of hydrogen adsorbed by the nickel was calculated and plotted against respective pressures. The values so obtained at atmospheric pressure are recorded in Table $\mathrm{I}$.

Preparation of Catalysts.-Nickel A was prepared by partially igniting the pure nitrate in a casserole over a small flame, transferring this material to the adsorption bulb and calcining at $300^{\circ}$ in a stream of air. The oxide was reduced at $300^{\circ}$ in a stream of pure, dry hydrogen until the amount of water absorbed from the effluent hydrogen by a weighed U-tube containing anhydrous calcium chloride did not exceed $2.5 \mathrm{mg}$. in an hour. This sample contained $15 \mathrm{~g}$. and was not completely reduced, since a somewhat higher temperature $\left(420^{\circ}\right.$ according to Senderens and Aboulenc) ${ }^{2}$ is necessary for complete reduction.

Nickel B consisted of $1 \mathrm{~g}$. of nickel supported upon $10 \mathrm{~g}$. of diatomaceous earth. It was prepared by soaking the support in nickel nitrate solution, drying and partly calcining at low temperature in a casserole. This material was then ground in a mortar, placed in an adsorption bulb and calcined at $300^{\circ}$ for 14 hours with a current of air passing through. Owing to the resistance of the material to the passage of gas, it was necessary to place the furnace in a horizontal position instead of in the vertical position used in the case of Nickel A. At $300^{\circ}$, reduction was extremely slow, having only commenced after passage of hydrogen for 26 hours as indicated by the color change of gray to black; the temperature was therefore increased to $350^{\circ}$ and pure, dry hydrogen passed through for 6.5 days longer. At the end of this time the gain in weight of the calciumchloride tube indicated $1.5 \mathrm{mg}$. of water taken from the effluent gas per hour.

Nickel C differed from Nickel B only in the fact that it was reduced for 40 minutes at $500^{\circ}$. A calcium chloride tube through which the exit gas was passed during the last 15 minutes of the reduction period showed no gain in weight at the end of the time. Nickel C consisted of $1.04 \mathrm{~g}$. of nickel on $9 \mathrm{~g}$. of diatomaceous earth.

Nickel D was prepared by soaking $6.75 \mathrm{~g}$. of diatomite (Non-Pareil) brick graded between 8- and 10-mesh sieves with a solution of pure nickel nitrate of such concentration that the resulting catalyst contained $10 \%$ of metallic nickel. The material was then calcined in a casserole at a low temperature and reduced in the adsorption bulb at $300^{\circ}$ with pure, dry hydrogen.

Nickel E consisted of $1 \mathrm{~g}$. of nickel supported on $9 \mathrm{~g}$. of diatomite brick graded as above. It was made by dissolving the required amount of pure nickel nitrate in sufficient water so that the brick just soaked up all the solution. The excess moisture was then evaporated, the material transferred to the adsorption bulb and calcined at $400^{\circ}$ in a stream of air. The resulting oxide was reduced in a stream of pure, dry hydrogen between $300^{\circ}$ and $500^{\circ}$ for 25 minutes, at the end of which time reduction was complete. The temperature was maintained at $500^{\circ}$ for 10 minutes.

All of these catalysts represent materials of a high degree of catalytic activity: As a criterion of their activity it may be stated that they would readily hydrogenate benzene vapor at $70^{\circ}$ and higher temperatures.

The gases were prepared by methods similar to those described by Taylor and Burns with additional refinements to secure greater purity.

${ }^{2}$ Senderens and Aboulenc, Bull. soc. chim., [4] 11, 641 (1912). 


\section{TABLE I}

Gas Volumes Adsorbed at 760 mm. Gas Pressure

\begin{tabular}{|c|c|c|c|c|c|c|c|c|c|c|c|c|}
\hline \multirow{2}{*}{$\begin{array}{l}\text { Sam } \\
\text { ple }\end{array}$} & \multirow{2}{*}{ Support } & \multirow{2}{*}{$\begin{array}{l}\text { Wt. } \\
\text { G. }\end{array}$} & \multirow{2}{*}{$\begin{array}{l}\text { Wt. Ni } \\
\text { G. }\end{array}$} & \multirow{2}{*}{ Gas } & \multicolumn{4}{|c|}{$\begin{array}{c}\begin{array}{c}\text { Cc. }(0-760 \mathrm{~mm} \text {.) ad- } \\
\text { sorbed by sample }\end{array} \\
\text {. }\end{array}$} & \multicolumn{4}{|c|}{$\begin{array}{l}\text { Cc. }(0-760 \mathrm{~mm} .) \text { ad- } \\
\text { sorbed per vol. of } \mathrm{Ni}\end{array}$} \\
\hline & & & & & $25^{\circ}$ & $184^{\circ}$ & $218^{\circ}$ & $305^{\circ}$ & $25^{\circ}$ & $184^{\circ}$ & $218^{\circ}$ & $305^{\circ}$ \\
\hline A & None & 15.0 & 15.0 & $\mathrm{H}_{2}$ & 8.7 & 7.9 & 7.0 & 5.4 & 5.2 & 4.7 & 4.2 & 3.2 \\
\hline B & Diat. earth & 11.0 & 1.1 & $\mathrm{H}_{2}$ & 6.30 & 6.15 & 5.65 & $\cdots$ & 50.7 & 49.8 & 46.3 & .. \\
\hline \multirow[t]{2}{*}{ C } & Diat. earth & 10.4 & 1.0 & $\mathrm{H}_{2}$ & 5.70 & 5.60 & 5.35 & .. & 50.7 & 49.8 & 47.2 & $\cdots$ \\
\hline & & & & $\mathrm{CO}_{2}$ & . & 1.8 & . & . & & 16.0 & .. & . \\
\hline E & Diatomite & 10.0 & 1.0 & $\mathrm{H}_{2}$ & $\begin{array}{l}4.8 \\
175^{\circ}\end{array}$ & $200^{\circ}$ & $225^{\circ}$ & $250^{\circ}$ & $\begin{array}{l}42.7 \\
175^{\circ}\end{array}$ & $200^{\circ}$ & $2 \overline{25}^{\circ}$ & $250^{\circ}$ \\
\hline \multirow[t]{3}{*}{ D } & Diatomite & 7.5 & 0.75 & $\mathbf{H}_{2}$ & 3.8 & 3.9 & .. & 3.5 & 46.3 & 45.4 & $\ldots$ & 42.1 \\
\hline & & & & $\mathrm{CO}_{2}$ & 1.3 & 1.2 & 1.1 & .9 & 15.1 & 14.2 & 13.4 & 11.8 \\
\hline & & & & $\mathrm{CO}$ & 5.25 & .. & . & . & 50.4 & . & .. & . \\
\hline
\end{tabular}

Comparison of the results for Nickel A with those of Taylor and Burns illustrates the fact that the previous history of the sample may have no little effect upon the capacity which it exhibits for adsorbing hydrogen. The discrepancies in the literature may well be due in part to the treatment accorded the sample before adsorption measurements were made. These have been considered by Taylor and Burns. ${ }^{1}$ In this connection, it is to be noted that the values given in the tables represent a steady state of adsorptive capacity. The first experiment after the reduction of Sample A showed an adsorption of $10.4 \mathrm{cc}$. at $25^{\circ}$. The second was at $80.5^{\circ}$ (see Fig. 2) with a value of $9.3 \mathrm{cc}$. The value of $8.7 \mathrm{cc}$. at $25^{\circ}$ is the mean of a number of values ranging from $8.5 \mathrm{cc}$. to $8.9 \mathrm{cc}$. obtained after numerous experiments at different temperatures. As a check, a run was made at this temperature after the final run at $305^{\circ}$ and the value of $8.5 \mathrm{cc}$. was obtained, which is evidence of a steady adsorptive capacity.

The effect of supporting the metal on an inert material was to increase its capacity for adsorbing hydrogen almost 10 -fold, which may be explained on the basis of increased effective surface. An additional advantage of using a support material such as diatomaceous earth lies in the fact that the catalyst may be subjected to more severe heating in the reduction process without destruction of its adsorbing power. Sample $\mathrm{C}$ was maintained at $500^{\circ}$ for 40 minutes during the course of reduction, yet showed practically the same adsorbing power as did Sample B which was reduced at $350^{\circ}$. Sample E supported on diatomite brick was reduced at $500^{\circ}$ for 10 minutes and showed an adsorptive capacity only slightly less than that of Sample D on diatomite brick reduced at $300^{\circ}$. These results are in good agreement with those of Kelber and of Armstrong and Hilditch ${ }^{3}$ who showed that nickel hydroxide precipitated on diatomaceous earth and reduced at $500^{\circ}$ is an extremely active catalyst. Taylor and Burns ${ }^{1 b}$ have shown that heating the nickel to $600-700^{\circ}$ decreases the adsorption

${ }^{3}$ Kelber, Ber., 49, 55, 1868 (1916). Armstrong and Hilditch, Proc. Roy. Soc., 99A, 490 (1921). 
between 80 and $97 \%$, and Sabatier ${ }^{4}$ states that nickel reduced at $700^{\circ}$ is practically inert as a catalyst. Armstrong and Hilditch ${ }^{3}$ have shown that ignition of an unsupported catalyst at $500^{\circ}$ in hydrogen is sufficient to impair seriously its catalytic activity. This influence of the support material is of considerable importance, since complete reduction cannot be attained at a temperature below $420^{\circ} .2$

It is also worthy of note that the oxide when supported on diatomaceous earth cannot be reduced at a temperature below $350^{\circ}$ excepting extremely slowly, whereas unsupported nickel is rapidly reduced at this temperature. The explanation of this phenomenon is by no means immediately apparent. The molecular heat of formation of nickel oxide is 59,700 calories,

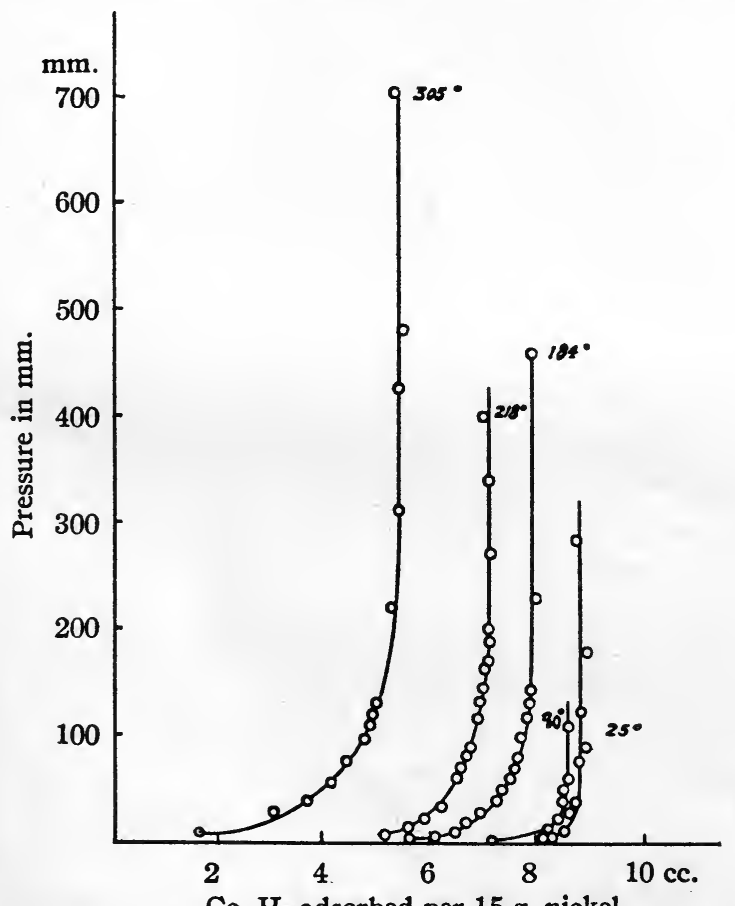

Cc. $\mathrm{H}_{2}$ adsorbed per $15 \mathrm{~g}$. nickel.

Fig. 1.

whereas the molecular heat of formation of water vapor is 58,100 calories; the effect, therefore, cannot be due to local overheating in the unsupported material. It would appear that the reduction of nickel oxide is an interface phenomenon, as has been shown to be the case for the reduction of copper oxide by hydrogen. ${ }^{5}$ When the nickel oxide is spread over an inert surface, the action is probably much more discontinuous and more or less

"Sabatier, "La Catalyse en Chimie Organique," Libraire Polytechnique, Ch. Beranger, Editeur, 1920, p. 134.

- Pease and Taylor, J. Am. Chem. Soc., 43, 2188 (1921). 
limited to two dimensions, whereas in the case of massive nickel oxide the spread of reduction may take place in every direction throughout the mass, and therefore reduction, under a given set of conditions, will be much more rapid in the latter case than in the former. Whether other factors contribute to this anomalous behavior is worthy of further experimental investigation.

\section{The Adsorption Isotherms of Hydrogen on Nickel}

The influence of pressure on the adsorption of hydrogen by Sample A was studied at temperatures of $25^{\circ}, 80.5^{\circ}, 184^{\circ}, 218^{\circ}$ and $305^{\circ}$. In Figs. 1 and 2 , the volumes of gas in cubic centimeters at $0^{\circ}-760 \mathrm{~mm}$. are plotted against the pressures at the several temperatures studied. The curves show the characteristic shape of normal adsorption isotherms with no discontinuities indicative of compound formation but with the distinction that at certain pressures a definite saturation capacity is reached at each temperature. The difference is apparent in Fig. 2 where Curve I shows the adsorption isotherm of hydrogen on nickel at $80.5^{\circ}$, Curve II the type (not drawn to scale) of curve obtained in the case of the dissociation of a salt hydrate, and Curve III represents the adsorption isotherm of hydrogen on charcoal at $0^{\circ}$ taken from results of Titoff. ${ }^{6}$ As Bancroft ${ }^{7}$ has pointed out, curves of the type

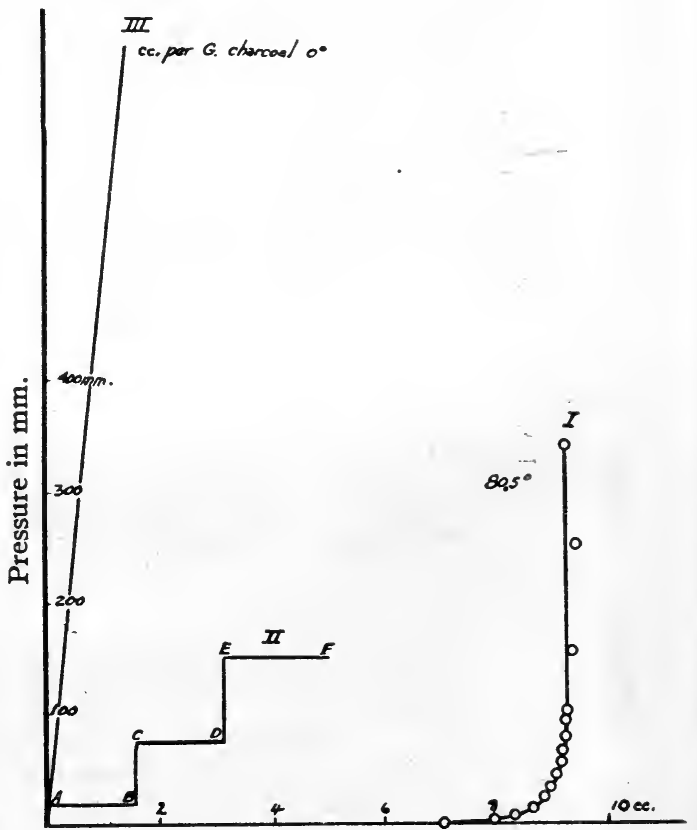

Cc. $\mathrm{H}_{2}$ adsorbed per $15 \mathrm{~g}$. nickel.

Fig. 2. shown in Fig. 1 represent either a continuous series of solid solutions or adsorption. Arguments for the latter are the rapidity with which equilibrium: is reached and the fact that the action does not follow Henry's law. It: is also to be noted that the influence of surface is further indication that adsorption is involved.

6 Titoff, Z. physik. Chem., 74, 64 (1910).

7 W. D. Bancroft, "Applied Colloid Chemistry," McGraw-Hill Book Co.. Inc., New York, 1921, p. 34 . 
The adsorptive capacity is not independent of temperature, for a different saturation value or limit exists at each temperature. The effect of increased temperature is to lower the saturation value, which means that the number of spaces which can be occupied by gas molecules is less at high temperatures than at low. Why this should be the case is by no means obvious. The increased kinetic energy of some of the surface molecules may be so great, due to the temperature increase, that all the hydrogen atoms striking the surface cannot remain thereon even momentarily. This would point to different adsorptive activities of individual atoms in the metal surface, a conclusion for which we have support from other experimental studies.

\section{Discussion of the Isotherms and Calculation of the Heat of Adsorption of Hydrogen on Nickel}

Studies of the influence of pressure on the adsorption of hydrogen by adsorbents such as charcoal and the zeolite, chabazite, have indicated that the amount of hydrogen adsorbed increased continuously with pressure

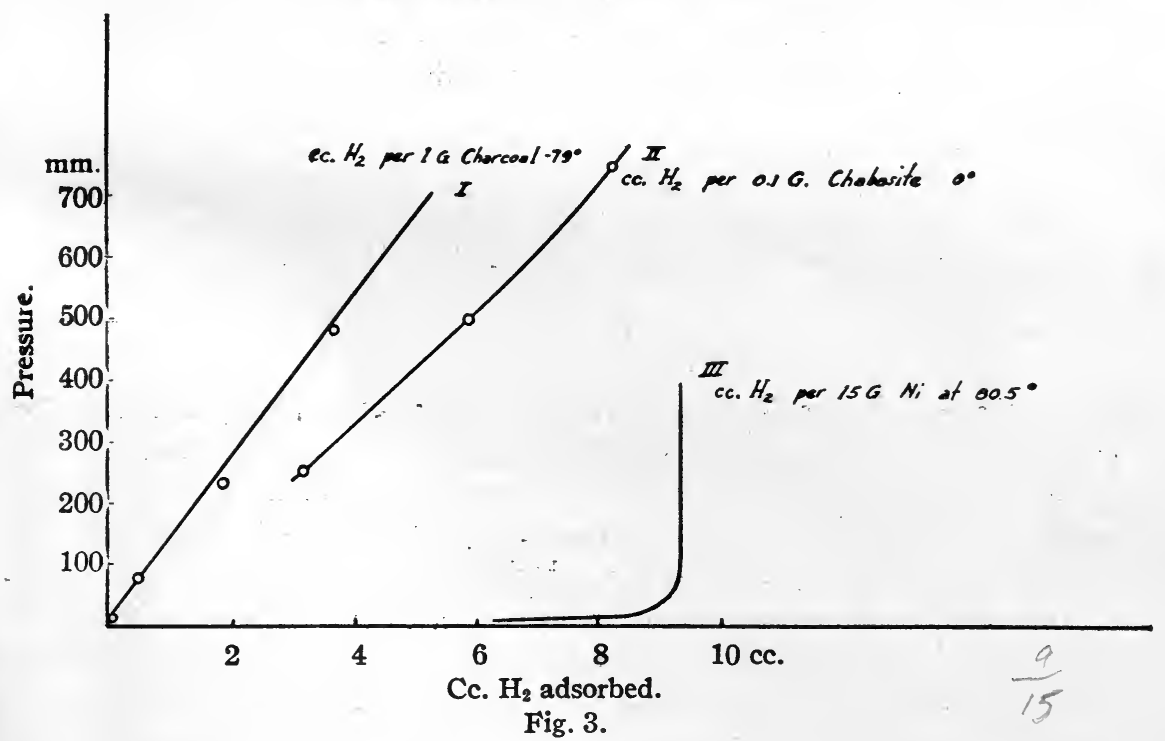

with no evidence of a limiting or saturation value. The results obtained by Titoff ${ }^{6}$ for hydrogen on charcoal (Curve I) and by Seeliger ${ }^{8}$ for hydrogen on chabazite (Curve II) are shown graphically in Fig. 3, along with one of the isotherms for hydrogen on nickel (Curve III) for purposes of comparison. The striking feature is that a definite saturation capacity exists at each temperature in the case of hydrogen on nickel. At this saturation pressure $(P)$, nickel saturated with hydrogen is in equilibrium with hydro-

${ }^{8}$ Seeliger, Physik. Z., 22, 563 (1921). 
gen at pressure $P$ and for comparison of the isotherms at different temperatures, $P$ may be taken as a corresponding condition. The condition is one of equilibrium; therefore, plotting the logarithm of the saturation pressure against the reciprocal of the absolute temperature should give a straight line. These pressures were selected as closely as is possible from the data and, thus plotted, gave a good approximation to a straight line.

We may relate the variation of the saturation pressure to the absolute temperature by means of the Clapeyron equation and thus calculate the heat of evaporation of adsorbed hydrogen from the nickel surface

$$
\frac{\mathrm{d} \ln P}{\mathrm{~d} T}=\frac{\lambda}{R T^{2}}
$$

where $P$ is the saturation pressure in mm. of mercury; $T$, the absolute temperature; $\lambda$, the heat of evaporation per gram-molecule, and $R$ is the gas constant in calories, $=1.99$. Integrating Equation 1 and passing to Briggsian logarithms,

$$
\lambda=1.99 \times 2.303 \frac{T_{1} T_{2}}{T_{2}-T_{1}} \log \frac{P_{2}}{P_{1}}
$$

the following table indicates values of $\lambda$ obtained by the use of different pairs

\begin{tabular}{|c|c|c|c|c|c|c|c|c|}
\hline${\stackrel{T}{{ }^{\prime}}}^{\mathrm{C} .}$ & ${ }^{T_{2}} \mathrm{C}$. & $\begin{array}{l}\lambda_{\text {oalo. }} \\
\text { Cal. }\end{array}$ & ${ }^{T_{1}}{ }_{\mathrm{C}}$. & ${ }^{T_{2}} \mathrm{C}$. & $\begin{array}{c}\lambda_{\text {oalo. }} \\
\text { Cal. }\end{array}$ & $\begin{array}{l}T_{1} \\
0^{2} \mathrm{C} .\end{array}$ & ${\stackrel{T}{T_{3}}}^{\mathrm{C}} \mathrm{C}$. & $\begin{array}{l}\lambda_{\text {oalo. }} \\
\text { Call. }\end{array}$ \\
\hline 80 & 25 & 2410 & 184 & 80 & 1720 & 218 & 184 & 3590 \\
\hline 184 & 25 & 2025 & 218 & 80 & 2076 & 305 & 184 & 3300 \\
\hline 218 & 25 & 2200 & 305 & 80 & 2382 & 305 & 218 & 3200 \\
\hline 305 & 25 & 2385 & $\cdots$ & .. & $\cdots$ & $\cdots$ & $\cdots$ & $\cdots$ \\
\hline & & & & & & & & 529 \\
\hline
\end{tabular}
of saturation pressures and the corresponding temperatures.

The heat of evaporation and, therefore, the heat of adsorption of hydrogen on nickel given by this method is approximately 2500 calories. This value was also obtained from the slope of the curve in the plot of the logarithm of saturation pressures against reciprocal of absolute temperature.

Ridea ${ }^{9}$ has recently studied the velocity of the following reaction, $\mathrm{C}_{2} \mathrm{H}_{4}$ $+\mathrm{H}_{2}=\mathrm{C}_{2} \mathrm{H}_{6}$, in the presence of nickel catalyst. Assuming that the rate of reaction in the presence of traces of oxygen is proportional to the rate of evaporation of hydrogen from the surface, he has plotted the velocity against the reciprocal of the absolute temperature and obtained a straight line. From the slope of the curve, Rideal calculates the heat of evaporation of hydrogen from the nickel surface to be equal to 12,000 calories per grammolecule. It may be observed that the value obtained by Rideal is dependent on several assumptions with regard to the mechanism of the hydrogenation of ethylene in presence of minute quantities of oxygen operating as a poison. The deduction in this case, therefore, of the thermal quantity involved in the evaporation of hydrogen from the nickel surface

- Rideal, J. Chem. Soc., 121, 309 (1922). 
is less direct than our own. The magnitude of the divergence, however, and the importance of this quantity in the theory of the subject warrant a more direct determination of the heat of adsorption. This is being attempted in this Laboratory. There are manifest difficulties in the performance of the experiment. It is of interest to record that recent calculations of Eucken ${ }^{10}$ of the work necessary to remove a film of adsorbed hydrogen from the surface of charcoal gave a value of 2500 calories, and in the case of other adsorbed gases similar low values were obtained.

\section{Summary}

1. Adsorption isotherms of hydrogen on nickel have been determined using nitrogen as reference gas.

2. A definite saturation capacity of nickel for hydrogen exists, dependent upon the temperature.

3. From the variation of the saturation pressure with temperature the heat of adsorption of hydrogen on nickel has been calculated to be approximately 2500 calories. Other methods of calculation give a value of 12,000 calories. A direct determination is being attempted.

4. The effect of using an inert material for catalyst support has been found to increase greatly the adsorptive capacity per gram of nickel and to yield a catalyst that will stand much more severe heat treatment without diminution of its adsorbing power.

I wish to express my appreciation to Professor Hugh S. Taylor for the interest and advice given to me in the course of this investigation.

${ }^{10}$ Eucken, Z. Elektrochem., 28, 1 (1922). 


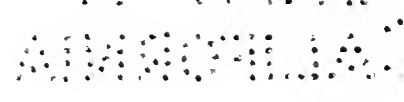




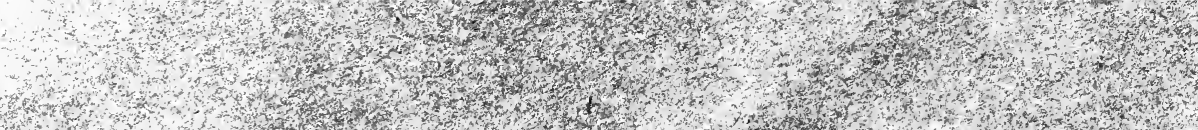

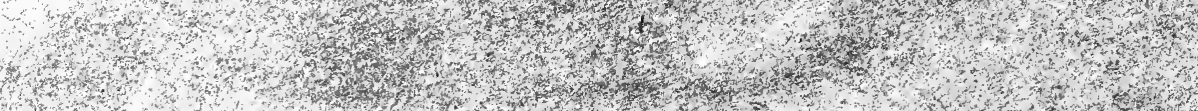

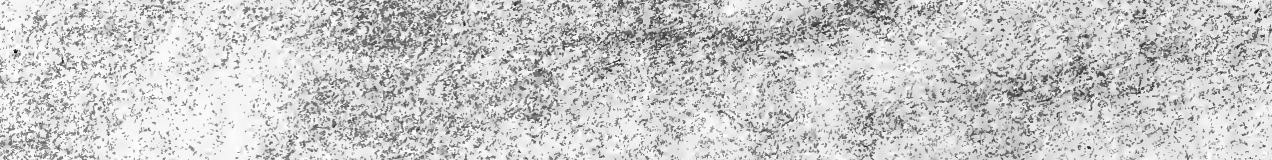

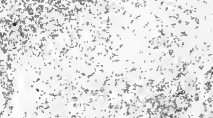

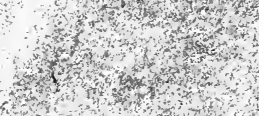

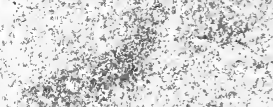

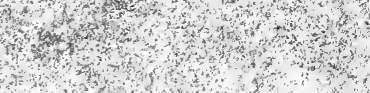

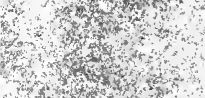

thes

3y

then

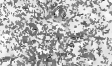

ty

atr 2

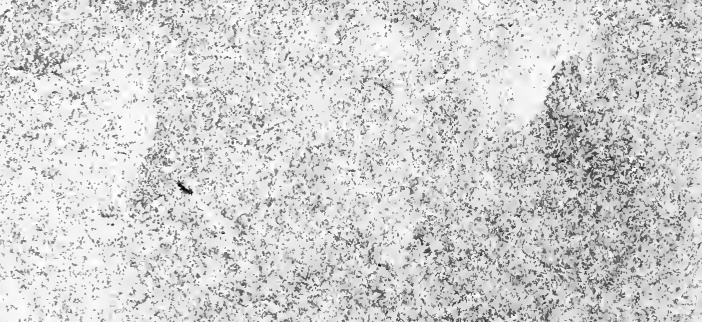

$x^{2}+x^{2}+x^{2}$

t.t.

1.2.

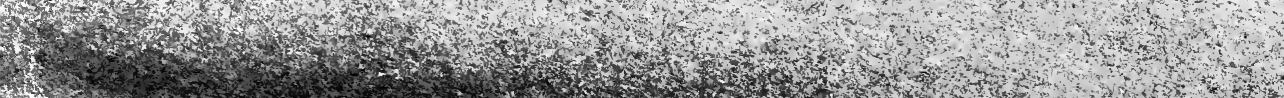

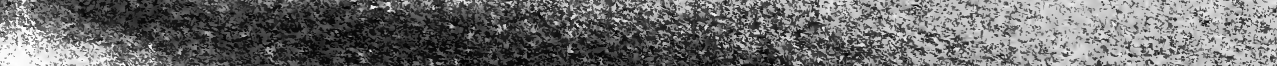

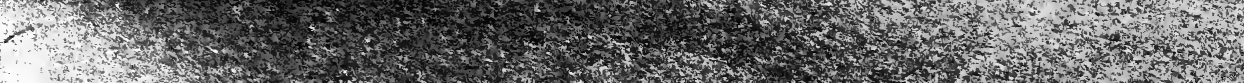

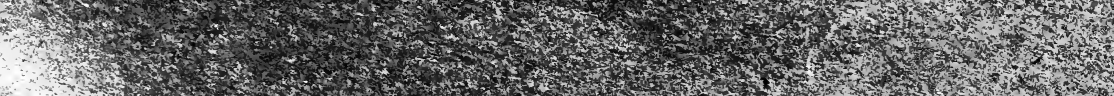
H. \begin{tabular}{ll}
11 \\
\hline
\end{tabular} 1
1

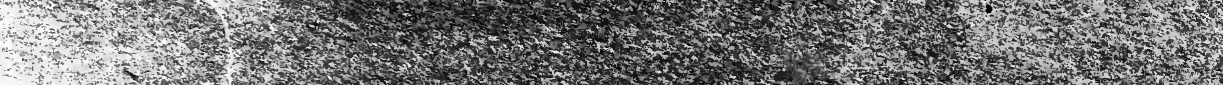

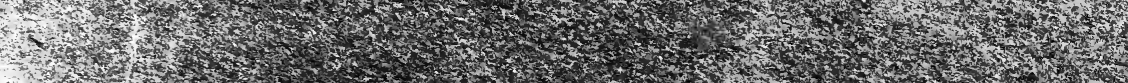
1.7. 4
0

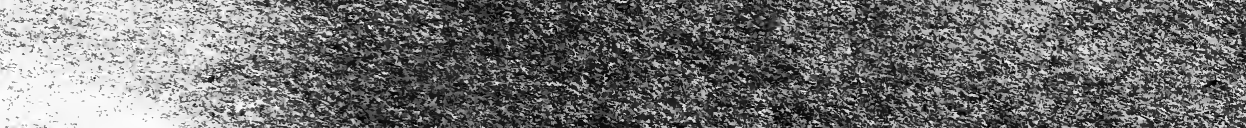

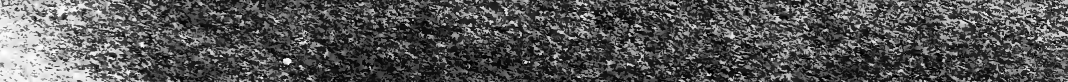

1.0. - . 1.t.

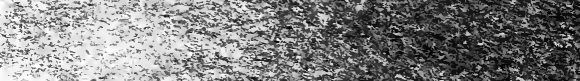

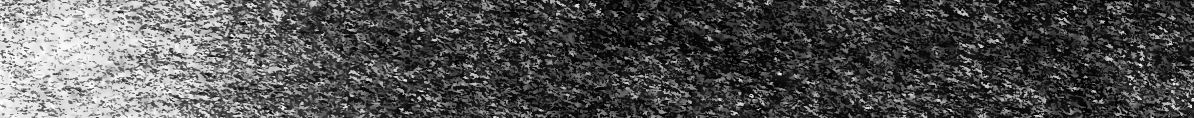

1
1

(n)

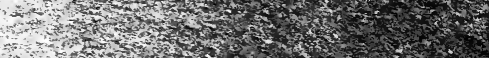

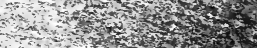

H.

$3-1, x_{1} x^{2}$ 

THIS BOOK IS DUE ON THE LAST DATE
STAMPED BELOW

AN INITIAL FINE OF 25 CENTS THIS BOOKSESSED FOR FAILURE TO RETURN WILL INCREASE THE DATE DUE. THE RETURN DAY AND TO TO 50 CENTS ON THE PENALTY OVERDUE. TO \$1.00 ON THE SEVENTH DAY

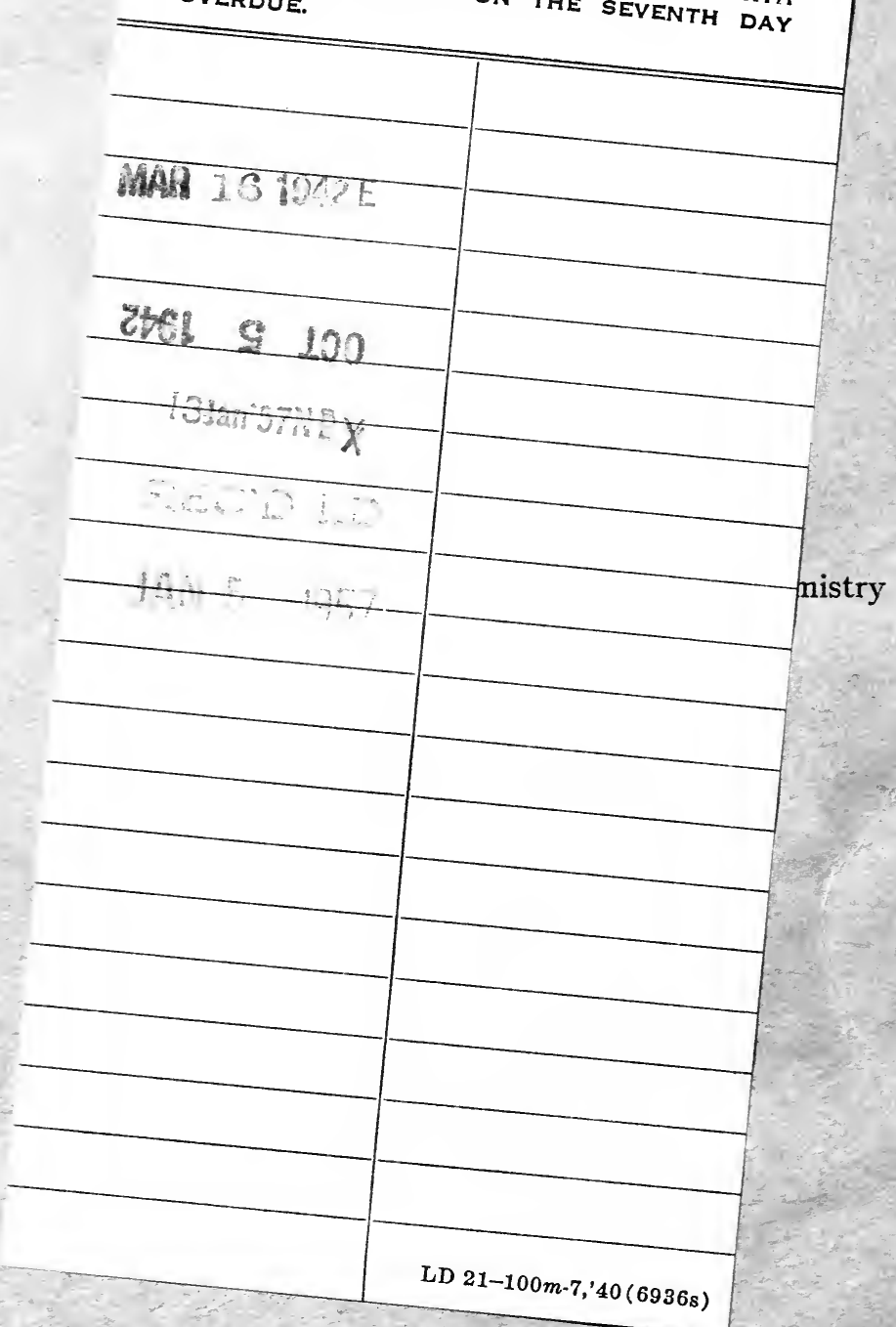




\section{$521: 344$}

UNIVERSITY OF CALIFORNIA LIBRARY 
